\title{
Projections of long-term changes in solar radiation based on CMIP5 climate models and their influence on energy yields of photovoltaic systems
}

\author{
Martin Wild ${ }^{1}$, Doris Folini ${ }^{1}$, Florian Henschel', Natalie Fischer ${ }^{1}$, Björn Müller ${ }^{2}$ \\ ${ }^{1}$ Institute for Atmospheric and Climate Science, ETH Zurich, Universitätsstr. 16, CH- \\ 8092 Zurich, Switzerland \\ ${ }^{2}$ Fraunhofer ISE, Fraunhofer Institute for Solar Energy Systems, Heidenhofstrasse 2, D- \\ 79110 Freiburg, Germany
}

Submitted to Solar Energy, October 18, 2014

In revised form, February 12, 2015 


\begin{abstract}
Traditionally, for the planning and assessment of solar energy systems, the amount of solar radiation (sunlight) incident on the Earth's surface is assumed to be constant over the years. However, with changing climate and air pollution levels, solar resources may no longer be stable over time and undergo substantial decadal changes. Observational records covering the past decades confirm long-term changes in this quantity. Here we examine how the latest generation of climate models used for the $5^{\text {th }}$ IPCC report projects potential changes in surface solar radiation over the coming decades, and how this may affect, in combination with the expected greenhouse warming, solar power output from photovoltaic (PV) systems. For this purpose, projections up to the mid $21^{\text {st }}$ century from 39 state of the art climate models from the Coupled Model Intercomparison Project Phase 5 (CMIP5) are analysed globally and for selected key regions with major solar power production capacity. The large model ensemble allows to assess the degree of consistency of their projections. Models are largely consistent in the sign of the projected changes in solar radiation under cloud-free conditions as well as surface temperatures over most of the globe, while still reasonably consistent over a considerable part of the globe in the sign of changes in cloudiness and associated changes in solar radiation. A first order estimate of the impact of solar radiation and temperature changes on energy yields of PV systems under the RPC8.5 scenario indicates statistically significant decreases in PV outputs in large parts of the world, but notable exceptions with positive trends in large parts of Europe and the South-East of China. Projected changes between 2006 and 2049 under the RCP8.5 scenario overall are on the order of $1 \%$ / decade for horizontal planes, but may be larger for tilted or tracked planes as well as on shorter (decadal) timescales.
\end{abstract}




\section{Introduction}

Solar radiation reaching the Earth's surface becomes an increasingly attractive resource to meet the rapidly growing energy demands of the world on a renewable carbon- and nuclear-free basis. Direct use of this resource through photovoltaic (PV) energy conversion has become the major contributor to this trend in recent years, reaching an installed capacity of more than $150 \mathrm{GW}$ in 2014 (EPIA, 2014).

Energy yields of PV systems first of all depend on the available amount of solar resources (i.e., the amount of solar radiation reaching the Earth's surface). In addition, changes in ambient temperatures have to be taken into account, since increasing ambient temperatures negatively affect PV power output. Other meteorological factors that influence energy yields of PV systems, such as wind, snow or the deposition of dust on the PV panels, are not further considered in the present study (see e.g., Huld et al., 2008 ; Reich et al., 2012; or Thevenard and Pelland, 2013 for more details on energy yields of PV systems).

Climate conditions relevant for the productivity of solar power plants may change over the coming decades subject to anthropogenic climate change. While changes in air temperature are a widely acknowledged aspect of climate change, potential changes in surface solar radiation have been discussed to a much lesser degree. For simplicity or lack of better knowledge, surface solar radiation is often assumed to remain constant over time. However, there is growing evidence from long term observational radiation records, that surface solar radiation undergoes substantial multidecadal variations, which should be considered in solar resource assessments (Müller et al., 2014; Wild, 2012). Coherent periods and regions with prevailing declines (known as "global dimming") and inclines (known as "brightening") in surface solar radiation have been detected in the worldwide observational networks, often in accord with anthropogenic air pollution patterns (Wild, 2009a; Wild, 2012; Wild et al., 2005). This suggests that anthropogenic air pollution and associated accumulation of aerosols in the atmosphere may have substantially contributed to the decadal variations in surface solar radiation. Specifically, the decline in surface

solar radiation at widespread observation sites from the 1950s to the 1980s is in line with the strongly increasing air pollution during this period, whereas the subsequent partial 
recovery of surface solar resources since the 1980s fits to the successive implementation of effective air pollution regulations, leading to a decline in aerosol burdens and more transparent atmospheres for solar radiation particularly in industrialized countries since the 1980s.

To estimate potential future changes in surface solar radiation and related meteorological quantities relevant for solar power production, however, we can obviously no longer use these observations, but have to rely on projections from comprehensive numerical models of the climate system. These models have become the primary tools for the development of climate change scenarios for the $21^{\text {st }}$ century, such as those released in the latest (fifth) assessment report of the Intergovernmental Panel on Climate Change (IPCC AR5) (IPCC, 2013).

Only a few studies so far used climate model projections to estimate multidecadal changes in solar resources under climate change and to assess the influence on solar energy applications. Remund and Müller (2010) presented solar radiation changes as projected with an earlier generation of climate models at the 10th European Conference on Applications of Meteorology (ECAM). Crook et al. (2011) used two versions of the Hadley Centre for Climate Prediction climate model to assess their projected changes in climate variables of relevance for solar power production. Using five regional climate models from the EU project ENSEMBLES, Panagea et al. (2014) estimate the impact of climate change on the PV energy output change in Greece. In Burnett et al. (2014) the impact of climate change is investigated across different regions of the UK by using the UKCP09 probabilistic climate change projections. Gaetani et al. (2014) use the ECHAM5 global climate model for an analysis of future changes of PV productivity in Europe and Africa.

Here we expand these studies, making use of the full set of latest generation climate models, which took part in the Coupled Model Intercomparison Project Phase 5 (CMIP5). With the comprehensive ensemble of projections from a total of 39 different climate models now available, the objective of this study is to assess the magnitude and degree of consistency in these numerous projections of changes in climate variables of relevance for solar power production. Crook et al. (2011) further made an attempt to estimate the impact of the changes in the relevant climate variables on solar power generation. We 
adopt their methodology to infer first order estimates of the potential consequences of the changes projected by this comprehensive ensemble of state of the art climate models for PV solar power generation.

\section{Data used in this study}

The data from climate model simulations used in this study stem from the CMIP5 project. CMIP5 provides a framework for the investigation and comparison of global coupled atmosphere-ocean models (AOGCMs) simulations by means of standardized experiments (Taylor et al., 2012). These experiments formed the basis for the assessment in the $5^{\text {th }}$ Intergovernmental Panel on Climate Change Assessment Report (IPCC, 2013).

Within CMIP5, predefined scenarios of radiative forcing obtained from socio-economic scenarios were used for the projections of climate change (Moss et al., 2010; van Vuuren et al., 2011). Four Representative Concentration Pathways (RCPs) were developed: $\mathrm{RCP} 2.6$, RCP4.5, RCP6 and RCP8.5, with the associated numbers indicating the radiative forcing reached at the end of the $21^{\text {st }}$ century compared to the preindustrial state. Central to the concept of the RCPs is that any single radiative forcing pathway can result from a diverse range of socioeconomic, technological and policy development scenarios. In this study, only experiments performed with RCP8.5 are considered. RCP8.5 thus relates to a radiative forcing of roughly $8.5 \mathrm{~W} / \mathrm{m}^{2}$ by 2100 relative to the pre-industrial period corresponding to an unabated increase of $\mathrm{CO}_{2}$ up to $940 \mathrm{ppm}$ at the end of the $21^{\text {st }}$ century (Riahi et al., 2011). This scenario ensures the highest signal-to-noise ratio, which facilitates the detection of significant change patterns. Note, however, that during the period analyzed in this study (up to 2050), the deviations between the different RCP scenarios are still fairly small, as they start to strongly diverge only after 2050. Therefore, with the time horizon considered here, the exact choice of the scenario is not so critical. Climate models under the RCP 8.5 scenario project on average a global warming of $2.0^{\circ} \mathrm{C}$ and $3.7^{\circ} \mathrm{C}$ until the mid and late $21^{\text {st }}$ century, respectively, relative to a reference period 1985-2005 (IPCC, 2013).

A list of the 39 models considered in this study with their related home institutions as well as their spatial resolution is given in Table 1. Only one ensemble run was included 
from each model in cases where multiple ensembles were available. Global annual fields of the following quantities are analysed: surface downward solar radiation (considering all weather conditions, commonly referred to as "all-sky"), surface downward solar radiation under cloud free conditions (referred to as "clear-sky"), near surface air temperature ("ambient temperature") and total cloud fraction.

As mentioned above, the scenarios are analysed for the period 2006 to 2049. In the experimental setup of CMIP5, the beginning of 2006 marks the transition from the historic simulations based on observed forcings to the scenario simulations using the assumed RCP forcings. Where necessary, a 10 year reference period 2006-2015 has been defined, which best represents present day conditions (Müller et al., 2014), so that the projected changes presented in this study are valid with respect to present day's conditions. 2049 was chosen as end year as a compromise to keep the period sufficiently long for a reasonable signal to noise ratio, but still short enough to scale with the typical life time for PV modules of up to 40 - 50 years.

For the analysis of the model data, all global fields were regridded to a common resolution of $480 * 240$ grid points. All results presented in this study are based on annual means. Note that clear-sky radiation fields were not available from the following models: CMCC-CESM, CMCC-CM, CMCC-CMS and EC-EARTH.

The abovementioned quantities were analyzed both on global and regional scales. Exemplary focal regions were defined based on the existing cumulative installed PV capacity (e.g. Germany and Spain) as well as on forecasts of the expected market development in the future (e.g. South Africa, India, Australia) (EPIA, 2014).. They are presented in Figure 1 and Table 2. Dimensions of the rectangular boxes covering these regions were chosen arbitrarily, but such that the high-capacity power plants in the respective region were covered. In each region, area averages were calculated by taking the area weighted mean of all grid points inside of the box boundaries.

\section{Results}

\subsection{Global projections of changes in radiation, cloud cover and temperatures}


Figure 2 shows global maps with linear trends of annual mean quantities between 2006 and 2049 for the following quantities: surface downward solar radiation under all-sky conditions (rsds) [W/m²/year], surface downward solar radiation under clear-sky conditions (rsdscs) [W/m²/year], near surface air temperature (tas) [K/year], and total cloud fraction (clt) [\%/year]. To illustrate the spread of model projections, the strongest negative or the smallest positive trends, respectively (declared as "smallest trends" in the first row), as well as the strongest positive or the smallest negative trends (declared as "largest trends" in the third row) are presented in addition to the median trends (second row). They were determined by taking the most extreme as well as the median trend values of all considered models at every grid point. Thus, at each grid point, the entire spread of all 39 model projections is indicated. Note that each map of smallest/largest trends does not necessarily originate from one single model, but is typically rather a composition of different models. White areas imply that the smallest/largest/median trends obtained this way at these grid points are statistically non-significant, based on a ttest with a significance level of 0.05 (Student, 1908).

For surface temperature, median trends show a distinct warming in northern latitudes, up to around $0.05 \mathrm{~K} /$ year over continents and approximately $0.02 \mathrm{~K} /$ year over oceans. The land/sea difference is caused by the significantly larger heat capacity of the oceans, which attenuate the warming compared to land areas. This pattern is intensified for the largest trends, where values exceed $0.1 \mathrm{~K} /$ year in large areas north of $50^{\circ} \mathrm{N}$ and reach around $0.07 \mathrm{~K} /$ year over land and $0.04 \mathrm{~K} /$ year over oceans. Models projecting the weakest warming show trends closer to zero in large parts of the world and a cooling in the NorthAtlantic and close to Antarctica down to more than $-0.1 \mathrm{~K} /$ year. In the regions relevant for solar power production (Table 2), the median prediction is a warming of around 0.05 $\mathrm{K} /$ year over the coming decades. Assuming no changes in solar radiation, this would imply decreasing power output for PV, due to its negative dependency on temperature (e.g., Huld et al., 2008).

Clear-sky radiation (rsdscs) changes fairly uniformly over the entire globe, median trends are slightly negative or close to zero, smallest and largest projected trends are around -0.1 $\mathrm{W} / \mathrm{m}^{2} /$ year and $0.05 \mathrm{~W} / \mathrm{m}^{2} /$ year respectively. Positive median trends are projected mainly 
for two regions, namely East- and Central-Europe and South-East China. This is likely the result of declining aerosol burdens in these areas.

Median trends for all-sky radiation (rsds) still show the pattern associated with clear-sky radiation, in addition to the effects of cloud cover (clt). Cloud cover tends to show the strongest decrease in the subtropics, between 20 to 40 degrees of latitude in both hemispheres (around -0.05\%/year). Included regions are the South-East of NorthAmerica, wide parts of Europe and China, the North of South-America, South-Africa, and Australia. In these regions, all-sky radiation increases by about $0.03 \mathrm{~W} / \mathrm{m}^{2} /$ year. Maximum values are observed in the South-East of China, reaching $0.4 \mathrm{~W} / \mathrm{m}^{2} /$ year for the median trends. In this region, positive clear-sky trends coincide with negative cloud cover trends. Minimum values of all-sky radiation trends are found in high latitudes mainly, where some models predict negative trends stronger than $-0.5 \mathrm{~W} / \mathrm{m}^{2} /$ year (i.e. stronger than $-0.5 \%$ /year considering an absolute amount of solar radiation of about 100 $\mathrm{W} / \mathrm{m}^{2}$ in these areas). This is in agreement with cloud cover trends, which are increasing by about $0.05 \% / y e a r$ according to median values, but can become considerably lager in some of the models.

Regarding the significance of the trends, surface temperature trends are significant worldwide, based again on a t-test with a significance level of 0.05. For clear-sky radiation, trends are mostly significant, and only regions in the transition zone from positive to negative trends show non-significant trends. All-sky radiation and total cloud fraction show larger areas with insignificant trends (white areas in Figure 2).

Similar patterns are observed in Figure 3, which allows an assessment of the degree of consistency amongst the various model predictions. Specifically, Figure 3 counts how many of the 39 models predict positive or negative trends at a particular grid point. A value of 1 signifies that $100 \%$ of the models show a positive trend, 0 signifies that $100 \%$ of the models show a negative trend. In contrast to Figure 2, Figure 3 does not make a statement on the strength of the trends. Comparing Figure 3 with Figure 2 indicates that models are typically more consistent (with respect to the sign of the trend) in regions where the median trends are most positive or negative, respectively.

While model predictions of all-sky radiation are consistent in the South-East of NorthAmerica and the Mediterranean Sea, they do not agree in those regions for clear-sky 
radiation. This may be due to the consistently predicted cloud cover changes in those regions, which dominate the all-sky trend. Due to this dependency we would expect two congruent maps for all-sky radiation and cloud cover. This is the case for large parts of the world, while it is not true for regions such as North-Africa and Northern India. However, in addition to cloud cover changes also clear-sky radiation changes play a role. Looking at the clear-sky radiation trends in Figure 2, we find that they are more negative in these regions, resulting in more negative trends in all-sky radiation and thus interfering with the pattern seen in cloud cover.

To sum up, while the signs of temperatures and clear-sky radiation changes are consistently predicted by the various models over most of the globe, also the signs of cloud and all-sky radiation changes, which are more difficult to predict for the models, are still fairly consistent in large parts of the globe. This suggests that projections of all sky radiation changes on these timescales are not purely random, but provide an overall reasonably consistent response pattern to the imposed forcings under the RCP8.5 scenario. This forms the justification for the more regional analysis in the following section.

\subsection{Projections of changes in radiation, cloud cover and temperatures in focal regions}

Figure 4 presents time series from 2006 to 2049 (annual mean) for all focal regions introduced in Table 2 / Figure 1, as well as the global mean. Shown are deviations from the first decadal mean (2006 to 2015). Each model realisation is represented as a black line, while the red line in each panel marks the median of the linear trends of the 39 models over this period. Note that different plots have different ranges for the y-axis.

Median trends for surface temperature (tas) are positive in all regions as well as in the global mean $(0.033 \mathrm{~K} /$ year), as expected from the global maps in Figure 2. They reach a maximum in China $(0.049 \mathrm{~K} /$ year) and a minimum in Germany $(0.036 \mathrm{~K} /$ year). All chosen regions thus show larger trends than in the global mean, which is expected due to faster warming over land than over oceans.

Clear-sky radiation (rsdscs) shows negative trends in the global mean $\left(-0.032 \mathrm{~W} / \mathrm{m}^{2} /\right.$ year) and throughout all regions except for Germany $\left(0.035 \mathrm{~W} / \mathrm{m}^{2} /\right.$ year $)$. The most negative trends are found in China $\left(-0.056 \mathrm{~W} / \mathrm{m}^{2} /\right.$ year $)$ and India $\left(-0.082 \mathrm{~W} / \mathrm{m}^{2} /\right.$ year $)$. Note that the 
region "China" as defined in Figure 1 and Table 2 does not correspond to the South-East of China, where strong positive trends are projected (see Figure 2).

The median of the all-sky radiation trends (rsds) shows positive values in most focal regions except for China $\left(-0.082 \mathrm{~W} / \mathrm{m}^{2} /\right.$ year) and India $\left(-0.089 \mathrm{~W} / \mathrm{m}^{2} /\right.$ year $)$, though a negative trend is found for the global mean $\left(-0.015 \mathrm{~W} / \mathrm{m}^{2} /\right.$ year $)$. Spain, which showed a slightly negative trend for clear-sky radiation $\left(-0.002 \mathrm{~W} / \mathrm{m}^{2} /\right.$ year $)$, shows the most positive trend for all-sky radiation $\left(0.115 \mathrm{~W} / \mathrm{m}^{2} /\right.$ year $)$. A similar behaviour is noted in Algeria, Australia, California and South-Africa. In the different seasons, most of these focal regions show qualitatively similar changes to the annual means in all-sky radiation (not shown). An exception states Germany, where the median trend in all-sky radiation is positive in summer, whereas no distinct trend is evident in during winter.

For all focal regions in Figure 4, annual cloud cover shows decreasing median trends, being most negative in Spain (-0.062 \%/year). Therefore, even though clear-sky radiation is declining, all-sky radiation may increase over time due to the decrease in cloud cover. The pattern of decreasing cloud cover throughout the focal regions is also depicted in the global mean (-0.006 \%/year), although Figure 2 indicates that outside the focal regions also regions with statistically significant positive cloud cover trends exist.

Overall, surface temperatures as well as all-sky radiation are projected to increase until 2049 by the CMIP5 models in most focal regions. Exceptions are China and India, where all-sky radiation declines.

To quantify the spread of model projections, trends of all models are presented in terms of box plots in Figure 5 for the different focal regions. The lower and upper end of the boxes represents the $25 \%$ and the $75 \%$ quartile, respectively. The range between both quartiles is defined as "interquartile range". The red line depicts the median, which divides the diagram into two halves, each including $50 \%$ of the data. The median is therefore less prone to outliers, which are presented as red crosses in the graph. The length of the whiskers is defined as maximal 1.5 times the interquartile range, which corresponds to around +-2.7 times the standard deviation if the data are normally distributed. However, whiskers only extend to the most extreme data point that lies within that range. Outliers indicated by red crosses are defined as data points beyond 1.5 times the interquartile range. 
Surface temperature trends (tas) show variations on the order of $0.05 \mathrm{~K} /$ year. Median values are around $0.04 \mathrm{~K} / \mathrm{year}$, as seen in Figure 2. Only one negative trend in form of an outlier is found in Australia. These observations confirm the robustness of temperature trends.

For clear-sky radiation, spreads are generally smaller than for all-sky radiation. The largest spreads are found here for India (slightly more than $0.2 \mathrm{~W} / \mathrm{m}^{2} /$ year) and Germany (around $0.15 \mathrm{~W} / \mathrm{m}^{2} /$ year). Taking outliers into account, projections for Australia also differ by around $0.2 \mathrm{~W} / \mathrm{m}^{2} /$ year. For the remaining regions, boxes and whiskers tend to be small (maximal $0.1 \mathrm{~W} / \mathrm{m}^{2} /$ year), implying consistent model projections.

As observed in Figure 4, trends of all-sky radiation tend to be positive in most regions except for China and India. However, Figure 3 highlights that for almost every region, there also exist models which project negative trends, which complicates predicting energy production of solar power plants. Not considering outliers, the spread of model projections is largest for Australia, Germany and Spain (all around $0.4 \mathrm{~W} / \mathrm{m}^{2} /$ year) and smallest for Algeria (less than $0.2 \mathrm{~W} / \mathrm{m}^{2} /$ year) (Figure 5).

This large spread is likely caused by cloud cover projections. For most regions, cloud cover trends with either sign are observed, resulting in median values close to zero, yet mostly negative. The spread of model projections mostly lies between 0.1 and $0.2 \% / y e a r$, with a maximum of $0.3 \% / y e a r$ for Australia when including outliers (Figure 5).

To sum up, most uncertainty arises from varying model projections for cloud cover, and therefore all-sky radiation. In contrast, surface temperature is rising worldwide, mostly independent of region and model. Both variables, all-sky radiation and surface temperature, are crucial for estimating PV yields, as further discussed in the following section.

\subsection{Implications for solar energy production}

Here we make a rough first order estimate to translate the projected changes in solar radiation and temperature into potential changes in PV solar power generation. We are aware that the chosen approach is fairly simplistic and cannot be more than a rough estimation of the order of magnitude of the impact of the projected changes in radiation and temperature on solar power production. The idea with this section is thus merely to 
illustrate the potential influence of the changes in solar radiation and temperature estimated above on PV power output. For the determination of PV solar power generation we follow closely the methodology presented in Crook et al. (2011).

Their estimates only depend on characteristics of the cell material, insolation and ambient air temperature (i.e. surface air temperature). The efficiency of the PV cell $\eta_{\text {cell }}$ is given by

$\frac{\eta_{\text {cell }}}{\eta_{\text {ref }}}=1-\beta\left(T_{\text {cell }}-T_{\text {ref }}\right)+\gamma \log _{10} G_{\text {tot }}$

where $\eta_{\text {ref }}$ is the reference efficiency and $G_{t o t}$ is the all-sky solar radiation. The coefficients $\beta$ and $\gamma$ are determined by the cell material and structure. As in Crook et al. (2011), values of $\beta=0.0045$ and $\gamma=0.1$ are used, representative for monocrystalline silicon cells., which dominate in the mass-production (Parida et al., 2011). $T_{\text {cell }}$ and $T_{\text {ref }}=25^{\circ} \mathrm{C}$ are the cell and the reference temperatures, respectively. According to Crook et al. (2011) and references therein, cell temperature may be expressed as

$T_{\text {cell }}=c_{1}+c_{2} T+c_{3} G_{\text {tot }}$

where $\mathrm{T}$ is the ambient air temperature in ${ }^{\circ} \mathrm{C}$. Coefficients $c_{1}, c_{2}$ and $c_{3}$ depend also on the cell properties. For monocrystalline silicon cells, values are $c_{1}=-3.75^{\circ} C, c_{2}=1.14$ and $c_{3}=0.0175^{\circ} \mathrm{Cm}^{2} W^{-1}$.

The final energy power output of a PV system is assumed to be

$P_{P V}=G_{t o t} \eta_{c e l l}$

Influences from other loss factors (e.g. angle of incident effects) or other system components (e.g. inverters) are neglected.

To eliminate $\eta_{\text {ref }}$ in the above equations, the fractional change in power output $\Delta P / P$ is examined. 
All our analyses, including the estimates of PV power output changes, are based on annual mean fields, whereas the methodology as presented in Crook et al. (2011) is based on monthly mean data. Potential non-linear effects due to the seasonal variations of radiation and temperature changes are therefore not considered in our estimates. To estimate their influence, we performed sensitivity calculations with the above formulations, using both annual and monthly radiation and temperature data as input. We found that the overall effects of using annual means instead of monthly means as originally used by Crook et al. (2011) had a negligible influence on the estimated changes in PV power output in all our focal regions. This justifies the use of annual mean radiation and temperature input for the present purpose.

Further more, irradiance data for the horizontal plane is used, neglecting possible changes in irradiance gains if the modules are mounted on a tilted plane.

Many of the global climate models show significant biases in terms of their representation of absolute levels of surface solar radiation and temperatures compared to surface observations (see e.g., Wild (2008) and Wild et al. (2013) for irradiance biases, Mueller and Seneviratne (2014) for temperature biases). This is largely related to difficulties associated with the parameterisation of cloud effects (e.g., Nam et al., 2012; Stanfield et al., 2014) as well as shortcomings in the representation of the clear sky radiation (Wild et al., 2006) in the models. In some studies bias corrections (e.g., Haerter et al., 2011) have therefore been applied on temperature and irradiance fields prior to the conversion into PV output (Panagea et al., 2014). To assess the influence of systematic biases in the simulated irradiance and temperature levels on the projected PV power output changes in the Crook et al. (2011) methodology, we performed sensitivity tests by shifting the absolute levels of the irradiance and temperature input in the Crook et al. (2011) formulations uniformly over time up to $+-10 \mathrm{Wm}^{-2}$ and $+-10^{\circ} \mathrm{C}$, respectively. We did not find a significant influence of these shifts in the absolute values on the projected changes in PV power output in all focal regions, indicating a low sensitivity of the Crook et al. (2011) methodology to the absolute levels of irradiance and temperature. We therefore did not apply bias corrections on the simulated temperature and irradiance fields prior to the conversion into PV power output (note also that bias corrections of irradiances on a global scale are to date far from being straightforward due to largely 
In the following, estimated PV power output changes will be presented. For each model, the fractional change of the power output between 2006 and 2049 relative to the first decadal mean (2006 to 2015) was determined using the above equations. Note that all changes presented here refer to changes representative for horizontal planes as given by the climate model output. Changes in solar radiation on tilted or tracked planes (i.e. planes oriented normal to the sunbeam) are typically larger, for example for tracked planes more than twice as large as respective changes on horizontal planes at sites in Germany, as evidenced by Müller et al. (2014). Median trends (\% /year) of all models are presented in Figure 6. White areas imply again non-significant trends, based on a t-test with a significance level of 0.05. The pattern of PV output changes in Figure 6 strongly resembles the trends of all-sky radiation (see Figure 2). This was to be expected since surface temperature, the second meteorological variable contributing to power output changes, increases uniformly in large regions of the world with the exception of polar regions in the northern hemisphere, which show exceptionally strong warming (Figure 2). As can be inferred from the above relationships, the PV output decreases with increasing temperatures. Accordingly, polar regions in the northern hemisphere with large temperature increases show a distinct decline in PV output. Negative trends in all-sky solar radiation add to this response.

Compared to the period between 2006 and 2015, PV output increases by 0.05 to 0.1 $\% / y e a r$ in the South-East of China, large parts of Europe, the South-East of NorthAmerica and small parts of South-America and Australia. In these regions, rising temperatures do not outweigh the increasing all-sky radiation. In some regions however (e.g. the Amazon and South-Africa), temperature changes are large enough to offset increased all-sky radiation. This causes PV output change to be statistically insignificant despite significant trends in all-sky radiation and temperature (compare with Figures 2 and 3). Decreasing trends of magnitude $-0.05 \% / y e a r$ are found inter alia in California, India and the North-West of China.

To summarize, we observe that surface temperature changes attenuate the PV power output, but that it is the all-sky radiation that governs the regional pattern. The overall 
pattern of median PV output changes presented in Figure 6 is reasonably similar to the one obtained by Crook et al. (2011) based on a single model (HadGEM1) and a former emission scenario (SRES A1B), albeit they project more negative changes in the Himalayas and equatorial Africa, and a smaller area of positive changes in South-East China.

In Figure 7 we estimate projected changes in PV power generation in our focal regions. Similar to Figure 6, Figure 7 shows trends of the fractional change of the power output between 2006 and 2049 relative to the first decadal mean (2006 to 2015). Values of all models are depicted as box plots. As in Figure 5, blue lines represent the $25 \%$ and the 75\% quartiles respectively, red lines the medians. Whiskers are presented in black, outliers as red crosses. Not considering outliers, the spread of all trends lies around 0.1 to $0.15 \% / y e a r$ for most regions. For Germany, an exceptionally large spread around 0.4 $\% /$ year is observed, which is likely the result of the wide spread seen in all-sky radiation (Figure 5). Median values are highest for Germany and Spain, where a relatively large change in solar radiation coincides with comparatively small changes in surface temperatures. Smallest median values are reached in China and India, which are the countries with the most negative all-sky radiation trends and most positive temperature trends.

Overall, out of the chosen eight regions, based on the simple relations to estimate solar power generation changes and the model-projected climate change scenarios, only Germany and Spain may profit from climate change in terms of PV energy production, whereas China and India are likely to face declining energy outputs. Germany and Spain are the only regions where substantially increasing all-sky radiation trends can compensate for rising surface temperatures (c.f. Figure 4). In the case of Germany, strong all-sky trends are reached as a result of positive clear-sky trends and decreasing cloudiness. Since clear-sky radiation decreases in all other focal regions, strongly decreasing cloud cover as projected for Spain is required for positive PV output changes. In summary for the focal regions, models indicate increasing potential for PV technology in Spain and Germany. On the other hand, energy production may decrease in the North of India and North-West of China. All these results are prone to uncertainties, especially since trends in some of the focal regions are not significant (c.f. Figures 6). 


\section{Discussion and conclusions}

The focus of this study has been on potential future changes in climate elements of relevance for PV solar power production, namely surface solar radiation and surface temperature. The study is based on the latest climate change projections from a large number of state of the art climate models (CMIP5) used in the framework of the latest $\left(5^{\text {th }}\right)$ IPCC assessment report. Decadal changes in all- and clear-sky surface solar radiation, cloud amount and surface temperature as projected up to 2050 in the RCP8.5 forcing scenarios of 39 GCMs have been analysed. Results have been discussed on the global scale as well as on worldwide distributed focal regions, where large volumes of PV have been installed or are under planning. Overall, the projections of the various models give a reasonably consistent picture of the changes to be expected in these climate elements. For surface temperatures, globally robust and statistically significant trends are observed, induced by the increasing concentration of greenhouse gases in the atmosphere. With respect to surface solar radiation, models are largely consistent in the projection of the sign of the changes over almost the entire globe under clear-sky conditions, and still over a considerable part of the globe when cloud effects are considered in addition (allsky conditions). Areas of consistently projected all-sky changes largely coincide with areas showing consistent changes in cloud amount in the majority of the models. Clearsky radiation is projected to decrease in most regions of the world, except for parts of China and Europe. Trends in this quantity are statistically significant almost globally.

Climate models, when compared to direct surface observations over the past decades, show a tendency to underestimate decadal variations in surface solar radiation (Allen et al., 2013; Wild and Schmucki, 2011). Also other model-simulated climate elements may be underestimated in their decadal climate variability compared to available observations such as the tropical top of atmosphere radiation budget (Wielicki et al., 2002), precipitation over land surfaces (Wild and Liepert, 2010) or specifically tropical precipitation (Allan and Soden, 2007), soil moisture (Li et al., 2007) and diurnal temperature range (Wild, 2009b). Longer term trends, such as the overall warming over the last century, are however realistically captured by the models. Therefore the projected 
changes in solar resources presented in this study quantitatively may indicate the overall direction of changes to be expected in the longer run, while on shorter timescales (decadal variability), changes may well be larger. Accordingly, this applies also for the estimated impacts of these changes on solar power production in PV systems derived here. Furthermore, changes in solar irradiance on tilted or tracked planes may be higher compared to the respective changes on horizontal plane investigated here (Müller et al., 2014). For Germany, it was shown that solar radiation trends on tracked planes (following the sun) more than double compared to trends on horizontal planes (Müller et al., 2014). Thus, given the RCP8.5 scenario, the estimated production changes on the order of $1 \%$ per decade may rather be seen as a conservative estimate for future solar power production changes due to changing solar resources.

Qualitatively, PV output is estimated to decrease in large parts of the world as a result of global warming and decreasing all-sky radiation over the coming decades. Positive trends are only projected to be reached in regions where cloud cover decreases substantially or clear-sky radiation increases, most notably in large parts of Europe and the South-East of China. Such scenarios may be combined in the future with spatially-resolved scenarios of PV system allocations, which are currently developed (Jerez et al., 2014).

This study emphasizes the importance of multidecadal changes in solar resources under changing climate, which, in combination with the expected greenhouse warming, may significantly affect PV yields over the coming decades.

\section{Acknowledgements}

We would like to thank Prof. Christoph Schär for the continuous support of our work. We are indebted to Dr. Urs Beyerle for his effort to download and organize the immense CMIP5 dataset. We acknowledge the international modeling groups for providing their data for analysis, the Program for Climate Model Diagnosis and Intercomparison (PCMDI) for collecting and archiving the model data, the JSC/CLIVAR Working Group on Coupled Modelling (WGCM) and their Coupled Model Intercomparison Project (CMIP) and Climate Simulation Panel for organizing the model data analysis activity, and the IPCC WG1 TSU for technical support. The IPCC Data Archive at Lawrence 
Livermore National Laboratory is supported by the Office of Science, U.S. Department of Energy.

\section{References:}

Allan, R.P. and Soden, B.J., 2007. Large discrepancy between observed and simulated precipitation trends in the ascending and descending branches of the tropical circulation. Geophysical Research Letters, 34(18): L18705.

Allen, R.J., Norris, J.R. and Wild, M., 2013. Evaluation of multidecadal variability in CMIP5 surface solar radiation and inferred underestimation of aerosol direct effects over Europe, China, Japan, and India. Journal of Geophysical ResearchAtmospheres, 118(12): 6311-6336.

Burnett, D., Barbour, E. and Harrison, G.P., 2014. The UK solar energy resource and the impact of climate change. Renewable Energy 71: 333-343.

Crook, J.A., Jones, L.A., Forster, P.M. and Crook, R., 2011. Climate change impacts on future photovoltaic and concentrated solar power energy output. Energ Environ Sci, 4(9): 3101-3109.

EPIA, 2014. Global market outlook for Photovoltaics 2014-2018, European Photovoltaic Industry Association (EPIA), Brussels.

Gaetani, M. et al., 2014. The near future availability of photovoltaic energy in Europe and Africa in climate-aerosol modelling experiments. Renewable and Sustainable Energy Reviews: in press.

Haerter, J.O., Hagemann, S., Moseley, C. and Piani, C., 2011. Climate model bias correction and the role of timescales. Hydrol Earth Syst Sc, 15(3): 1065-1079.

Huld, T., Suri, M. and Dunlop, E.D., 2008. Geographical Variation of the Conversion Efficiency of Crystalline Silicon Photovoltaic Modules in Europe. Prog Photovoltaics, 16(7): 595-607.

IPCC, 2013. Climate Change 2013: The Physical Science Basis. Contribution of Working Group I to the Fifth Assessment Report of the Intergovernmental Panel on Climate Change Cambridge, United Kingdom and New York, NY, USA.

Jerez, S. et al., 2014. The CLIMIX model: a tool to create and evaluate spatially-resolved scenarios of PV and wind power development. Renew. Sust. Energ. Rev.: in press.

Li, H.B., Robock, A. and Wild, M., 2007. Evaluation of Intergovernmental Panel on Climate Change Fourth Assessment soil moisture simulations for the second half of the twentieth century. Journal of Geophysical Research-Atmospheres, 112(D6): D06106.

Moss, R.H. et al., 2010. The next generation of scenarios for climate change research and assessment. Nature, 463(7282): 747-756.

Mueller, B. and Seneviratne, S.I., 2014. Systematic land climate and evapotranspiration biases in CMIP5 simulations. Geophysical Research Letters, 41

Müller, B., Wild, M., Driesse, A. and Behrens, K., 2014. Rethinking solar resource assessments in the context of global dimming and brightening. Solar Energy, 99: 272-282. 
Nam, C., Bony, S., Dufresne, J.L. and Chepfer, H., 2012. The 'too few, too bright' tropical low-cloud problem in CMIP5 models. Geophysical Research Letters, 39.

Panagea, I.S., Tsanis, I.K., Koutroulis, A.G. and Grillakis, A.G., 2014. Climate Change Impact on Photovoltaic Energy Output: The Case of Greece. Adv Meteorol.

Parida, B., Iniyan, S. and Goic, R., 2011. A review of solar photovoltaic technologies. Renew Sust Energ Rev, 15(3): 1625-1636.

Reich, N.H. et al., 2012. Performance ratio revisited: is PR > 90\% realistic? Prog Photovoltaics, 20(6): 717-726.

Remund, J. and Müller, S.C., 2010. Trends in global radiation between 1950 and 2100, 10th EMS Annual Meeting, 10th European Conference on Applications of Meteorology (ECAM). European Meteorological Society (EMS) Zürich.

Riahi, K. et al., 2011. RCP 8.5-A scenario of comparatively high greenhouse gas emissions. Climatic Change, 109(1-2): 33-57.

Stanfield, R.E. et al., 2014. Assessment of NASA GISS CMIP5 and Post-CMIP5 Simulated Clouds and TOA Radiation Budgets Using Satellite Observations. Part I: Cloud Fraction and Properties. Journal of Climate, 27(11): 4189-4208.

Student, 1908. The Probable Error of a Mean. Biometrika, 6(1).

Taylor, K.E., Stouffer, R.J. and Meehl, G.A., 2012. An Overview of Cmip5 and the Experiment Design. Bulletin of the American Meteorological Society, 93(4): 485498.

Thevenard, D. and Pelland, S., 2013. Estimating the uncertainty in long-term photovoltaic yield predictions. Solar Energy, 91: 432-445.

van Vuuren, D.P. et al., 2011. The representative concentration pathways: an overview. Climatic Change, 109(1-2): 5-31.

Wielicki, B.A. et al., 2002. Evidence for large decadal variability in the tropical mean radiative energy budget. Science, 295(5556): 841-844.

Wild, M., 2008. Short-wave and long-wave surface radiation budgets in GCMs: a review based on the IPCC-AR4/CMIP3 models. Tellus A, 60(5): 932-945.

Wild, M., 2009a. Global dimming and brightening: A review. Journal of Geophysical Research-Atmospheres, 114: D00d16.

Wild, M., 2009b. How well do IPCC-AR4/CMIP3 climate models simulate global dimming/brightening and twentieth-century daytime and nighttime warming? Journal of Geophysical Research-Atmospheres, 114: D00d11.

Wild, M., 2012. Enlightening Global Dimming and Brightening. Bulletin of the American Meteorological Society, 93(1): 27-37.

Wild, M. et al., 2013. A New Diagram of the Global Energy Balance. Aip Conf Proc, 1531: 628-631.

Wild, M. et al., 2005. From dimming to brightening: Decadal changes in solar radiation at Earth's surface. Science, 308(5723): 847-850.

Wild, M. and Liepert, B., 2010. The Earth radiation balance as driver of the global hydrological cycle. Environmental Research Letters, 5(2): Artn 025003.

Wild, M., Long, C.N. and Ohmura, A., 2006. Evaluation of clear-sky solar fluxes in GCMs participating in AMIP and IPCC-AR4 from a surface perspective. Journal of Geophysical Research-Atmospheres, 111(D1): D01104.

Wild, M. and Schmucki, E., 2011. Assessment of global dimming and brightening in IPCC-AR4/CMIP3 models and ERA40. Climate Dynamics, 37(7-8): 1671-1688. 
Table 1: CMIP5 models used in this study, with their host institution (first and second column), model acronym (third column) as well as their horizontal grid resolution (number of grid points, fourth/fifth column).

\begin{tabular}{|c|c|c|c|c|}
\hline $\begin{array}{l}\text { Modelling } \\
\text { Centre }\end{array}$ & Institution & Model & Long. & Lat. \\
\hline \multirow[t]{2}{*}{ CSIRO-BOM } & \multirow{2}{*}{$\begin{array}{l}\text { CSIRO (Commonwealth Scientific and Industrial Research } \\
\text { Organisation, Australia), and BOM (Bureau of Meteorology, } \\
\text { Australia) }\end{array}$} & ACCESS1.0 & 192 & 145 \\
\hline & & ACCESS 1.3 & 192 & 145 \\
\hline GCESS & $\begin{array}{l}\text { College of Global Change and Earth System Science, Beijing } \\
\text { Normal University }\end{array}$ & BNU-ESM & 128 & 64 \\
\hline NCAR & National Center for Atmospheric Research & CCSM4 & 288 & 192 \\
\hline \multirow{3}{*}{$\begin{array}{l}\text { NSF-DOE- } \\
\text { NCAR }\end{array}$} & \multirow{3}{*}{$\begin{array}{l}\text { National Science Foundation, Department of Energy, National } \\
\text { Center for Atmospheric Research }\end{array}$} & CESM1-BGC & 288 & 192 \\
\hline & & CESM1-CAM5 & 288 & 192 \\
\hline & & CESM1-WACCM & 144 & 96 \\
\hline \multirow[t]{3}{*}{$\mathrm{CMCC}$} & \multirow[t]{3}{*}{ Centro Euro-Mediterraneo per I Cambiamenti Climatici } & CMCC-CESM & 96 & 48 \\
\hline & & CMCC-CMS & 192 & 96 \\
\hline & & CMCC-CM & 480 & 240 \\
\hline $\begin{array}{l}\text { CNRM- } \\
\text { CERFACS }\end{array}$ & $\begin{array}{l}\text { Centre National de Recherches Meteorologiques / Centre } \\
\text { Europeen de Recherche et Formation Avancees en Calcul }\end{array}$ & CNRM-CM5 & 256 & 128 \\
\hline $\begin{array}{l}\text { CSIRO- } \\
\text { QCCCE }\end{array}$ & $\begin{array}{l}\text { Commonwealth Scientific and Industrial Research Organisation } \\
\text { in collaboration with the Queensland Climate Change Centre of } \\
\text { Excellence }\end{array}$ & CSIRO-Mk3.6.0 & 192 & 96 \\
\hline CCCma & Canadian Centre for Climate Modelling and Analysis & CanESM2 & 128 & 64 \\
\hline EC-EARTH & EC-EARTH consortium & EC-EARTH & 320 & 160 \\
\hline LASG-CESS & $\begin{array}{l}\text { LASG, Institute of Atmospheric Physics, Chinese Academy of } \\
\text { Sciences; and CESS, Tsinghua University }\end{array}$ & FGOALS-g2 & 128 & 60 \\
\hline LASG-IAP & $\begin{array}{l}\text { LASG, Institute of Atmospheric Physics, Chinese Academy of } \\
\text { Sciences }\end{array}$ & FGOALS-s2 & 128 & 108 \\
\hline FIO & The First Institute of Oceanography, SOA, China & FIO-ESM & 128 & 64 \\
\hline \multirow[t]{3}{*}{ NOAA GFDL } & \multirow[t]{3}{*}{ Geophysical Fluid Dynamics Laboratory } & GFDL-CM3 & 144 & 90 \\
\hline & & GFDL-ESM2G & 144 & 90 \\
\hline & & GFDL-ESM2M & 144 & 90 \\
\hline \multirow[t]{2}{*}{ NASA GISS } & \multirow[t]{2}{*}{ NASA Goddard Institute for Space Studies } & GISS-E2-H & 144 & 90 \\
\hline & & GISS-E2-R & 144 & 90 \\
\hline NIMR/KMA & $\begin{array}{l}\text { National Institute of Meteorological Research/Korea } \\
\text { Meteorological Administration }\end{array}$ & HadGEM2-AO & 192 & 145 \\
\hline
\end{tabular}




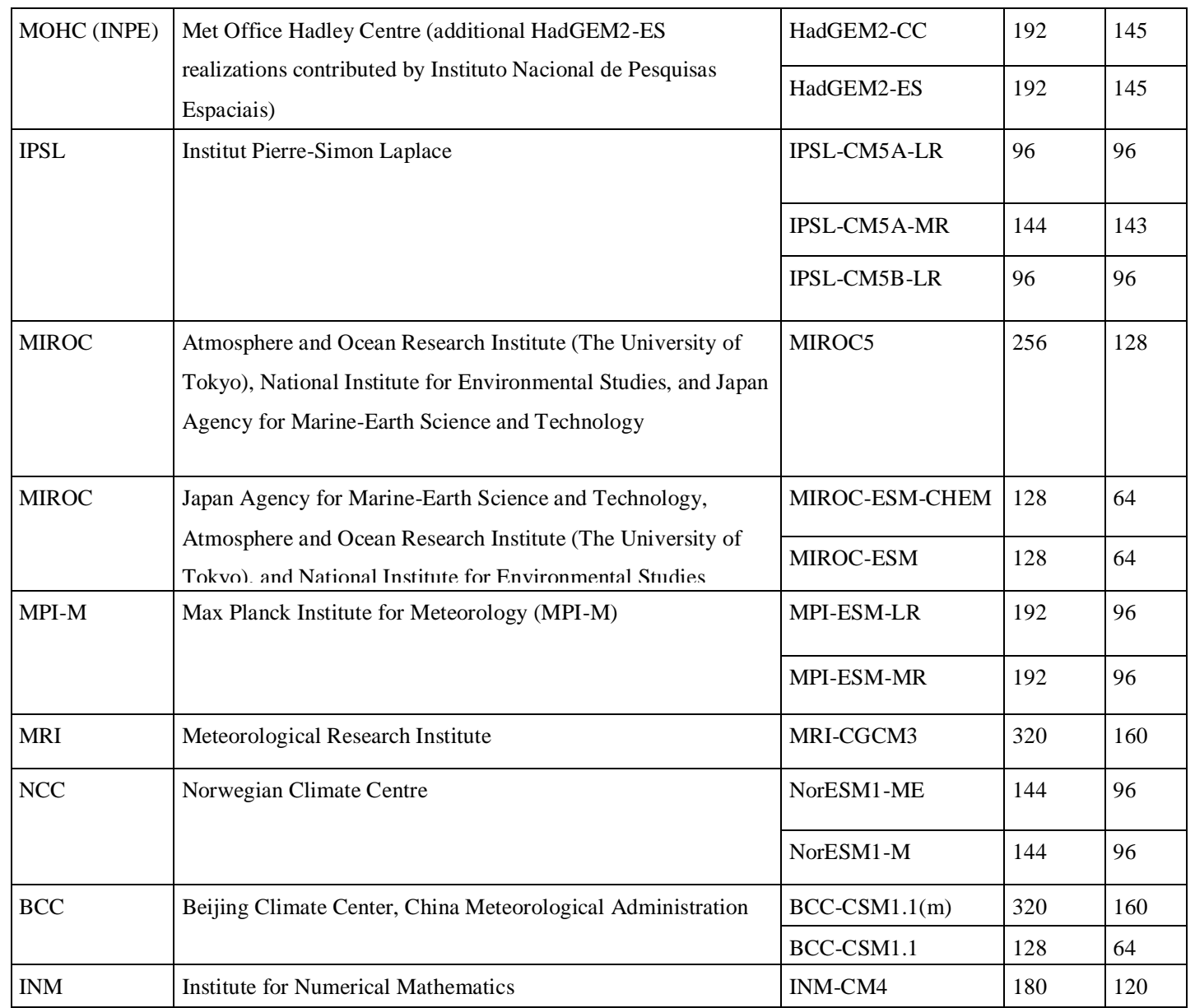


Table 2: Focal regions defined in this study containing some of the largest solar power plants and their boundary coordinates.

\begin{tabular}{|l|r|r|r|r|}
\hline & \multicolumn{3}{|c|}{ Boundaries [degrees] } \\
\hline $\begin{array}{l}\text { Region } \\
\text { name }\end{array}$ & West & East & $\begin{array}{r}\text { Sout } \\
\text { h }\end{array}$ & North \\
\hline Algeria & 0 & $10 \mathrm{E}$ & $30 \mathrm{~N}$ & $37 \mathrm{~N}$ \\
\hline Australia & $140 \mathrm{E}$ & $150 \mathrm{E}$ & $30 \mathrm{~S}$ & $20 \mathrm{~S}$ \\
\hline California & $122 \mathrm{~W}$ & $116 \mathrm{~W}$ & $32 \mathrm{~N}$ & $40 \mathrm{~N}$ \\
\hline China & $90 \mathrm{E}$ & $100 \mathrm{E}$ & $30 \mathrm{~N}$ & $40 \mathrm{~N}$ \\
\hline Germany & $5 \mathrm{E}$ & $15 \mathrm{E}$ & $47 \mathrm{~N}$ & $52 \mathrm{~N}$ \\
\hline India & $70 \mathrm{E}$ & $80 \mathrm{E}$ & $20 \mathrm{~N}$ & $30 \mathrm{~N}$ \\
\hline South Africa & $10 \mathrm{E}$ & $20 \mathrm{E}$ & $35 \mathrm{~S}$ & $20 \mathrm{~S}$ \\
\hline Spain & $8 \mathrm{~W}$ & 0 & $37 \mathrm{~N}$ & $42 \mathrm{~N}$ \\
\hline
\end{tabular}




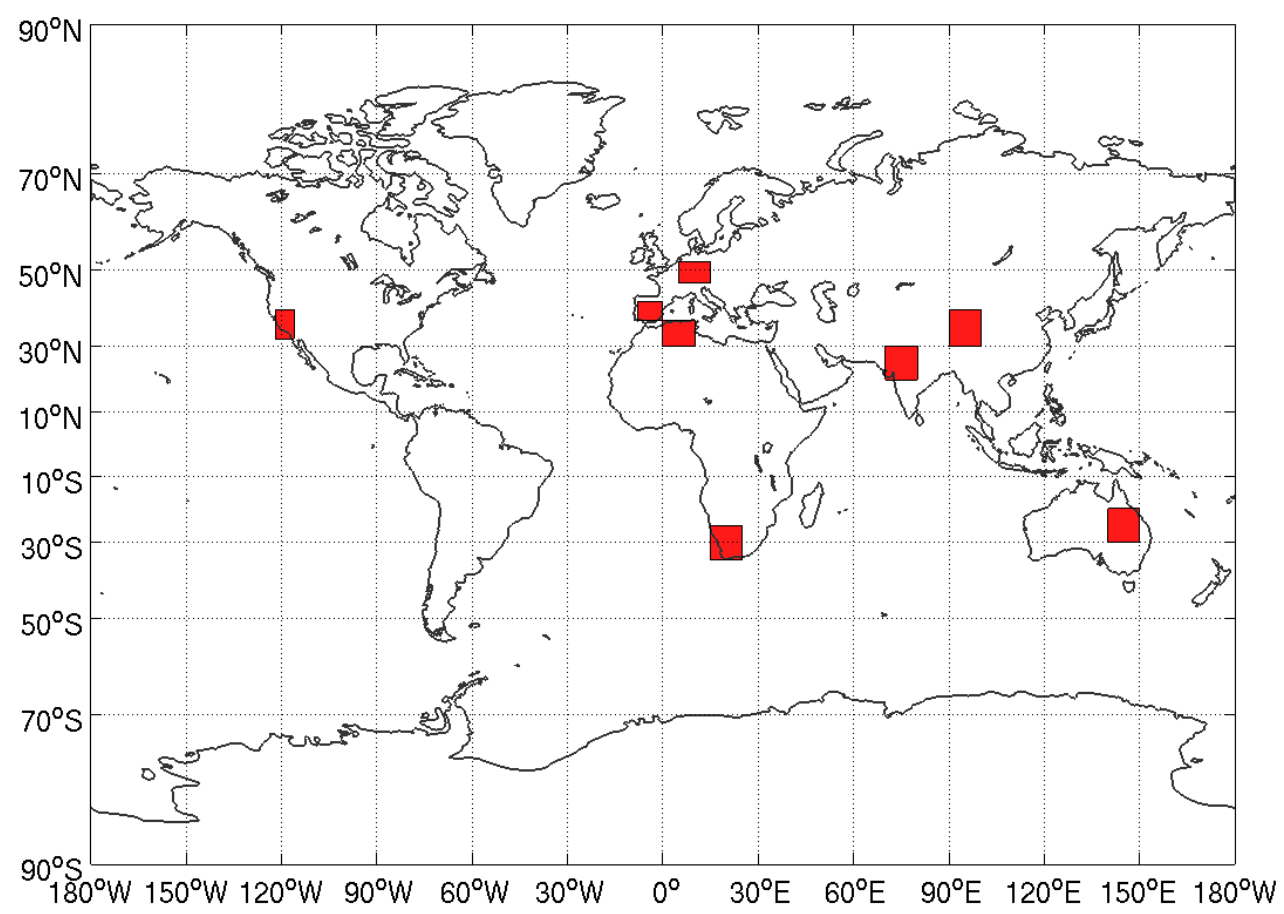

Figure 1: Focal regions considered in this study, displayed as red boxes. Definition of box boundaries given in Table 2. 

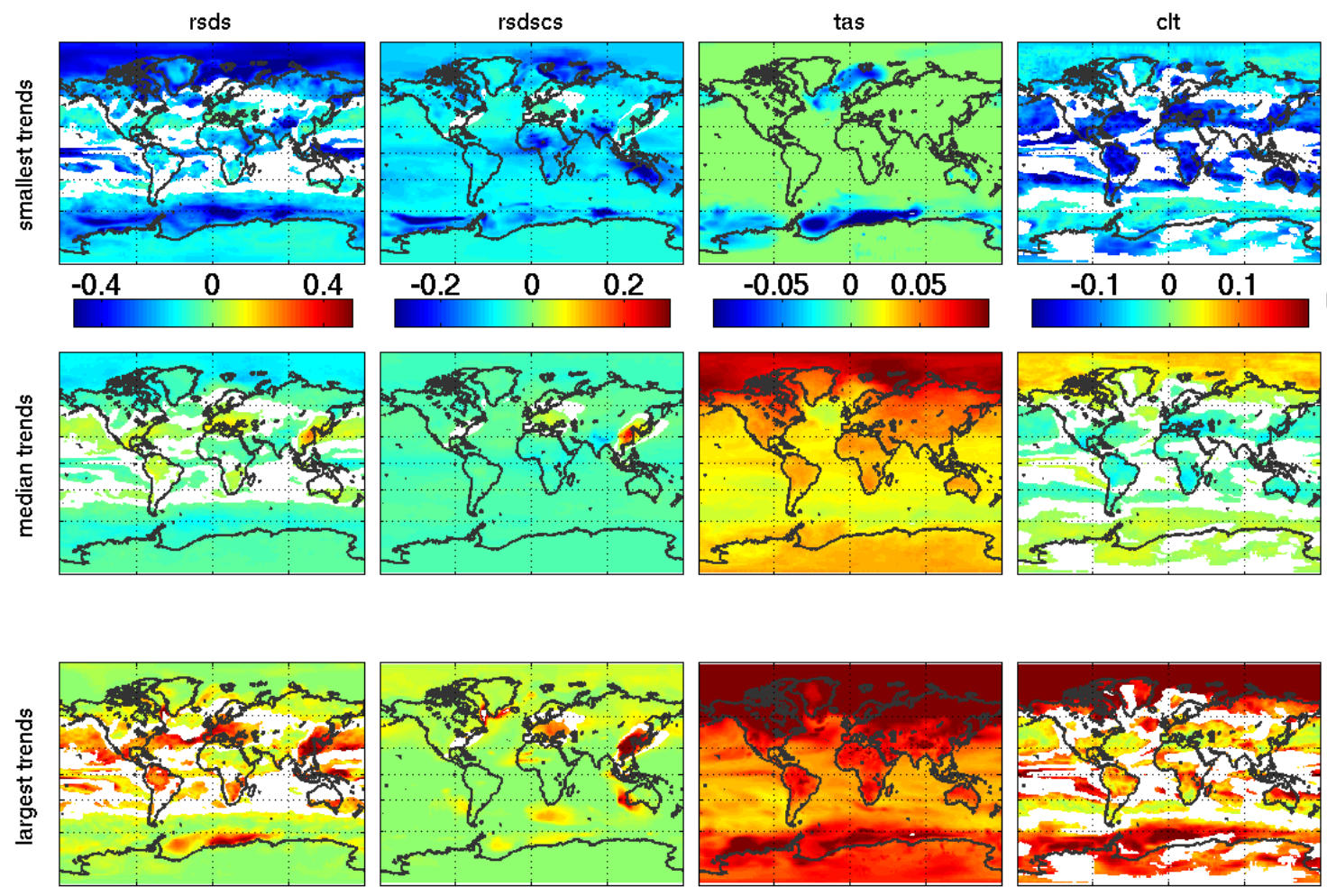

Figure 2: Global distribution of trends between 2006 and 2049 of surface downward solar radiation (rsds, first column) in [W/ $\mathrm{m}^{2} /$ year], surface downward clear-sky solar radiation (rsdscs, second column) in [W/ $\mathrm{m}^{2} /$ year], near surface air temperature (tas, third column) in [K/year] and total cloud fraction (clt, fourth column) in [\%/year]. Plotted are the most extreme trends (first and third row) as well as the median value (second row) of all considered models at every grid point. White areas indicate non-significant trends, based on a t-test with a significance level of 0.05 . Note that the range of all colour bars was restricted for reasons of clarity. 

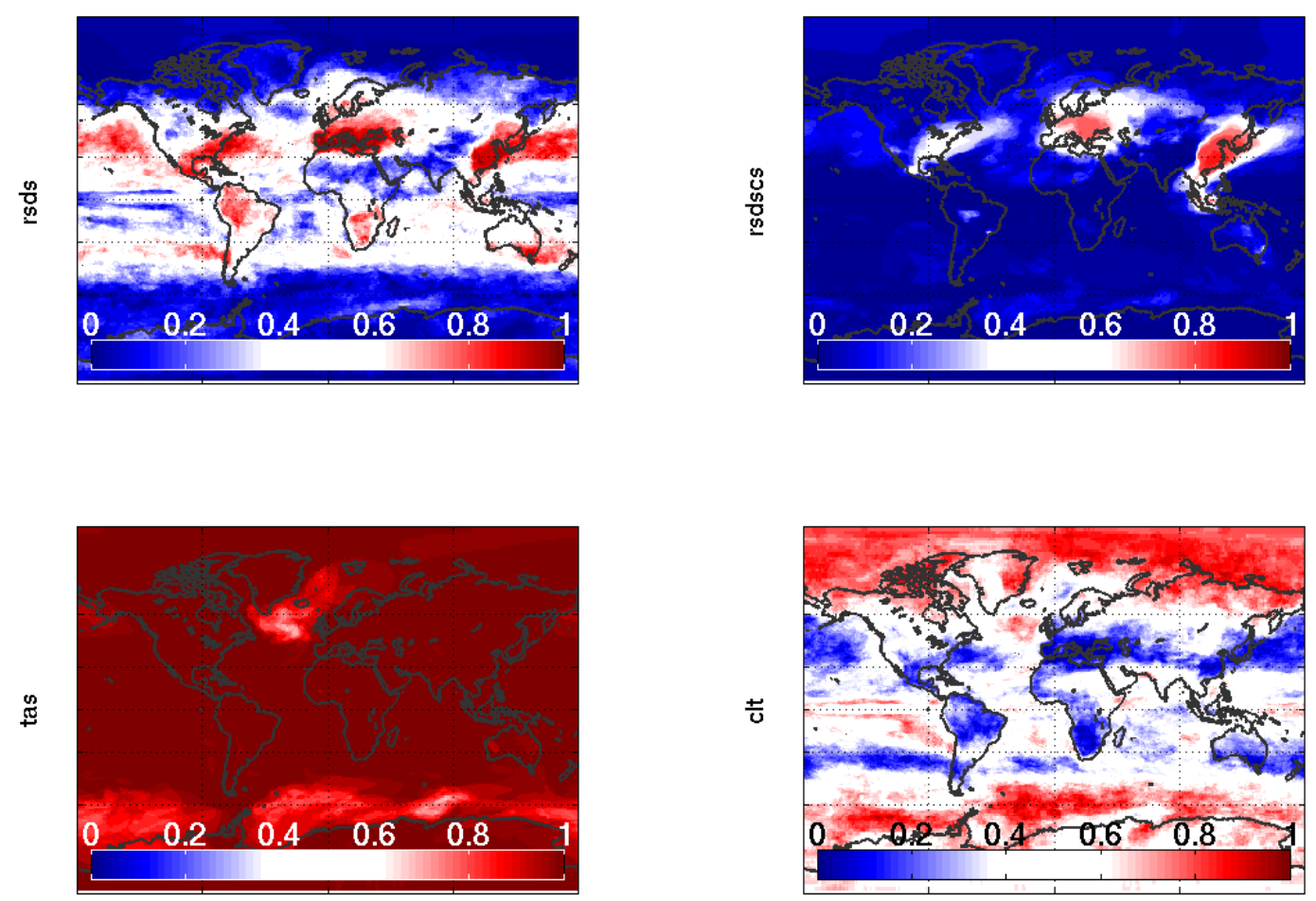

Figure 3: Consistency of model projections with respect to the sign of the trends between 2006 and 2049 in surface downward solar radiation (rsds), surface downward clear-sky solar radiation ( $\operatorname{rsdscs}$ ), near surface air temperature (tas) and total cloud fraction (clt). A value of 1 signifies that $100 \%$ of the models show a positive trend, 0 signifies that $100 \%$ of the models show a negative trend. 

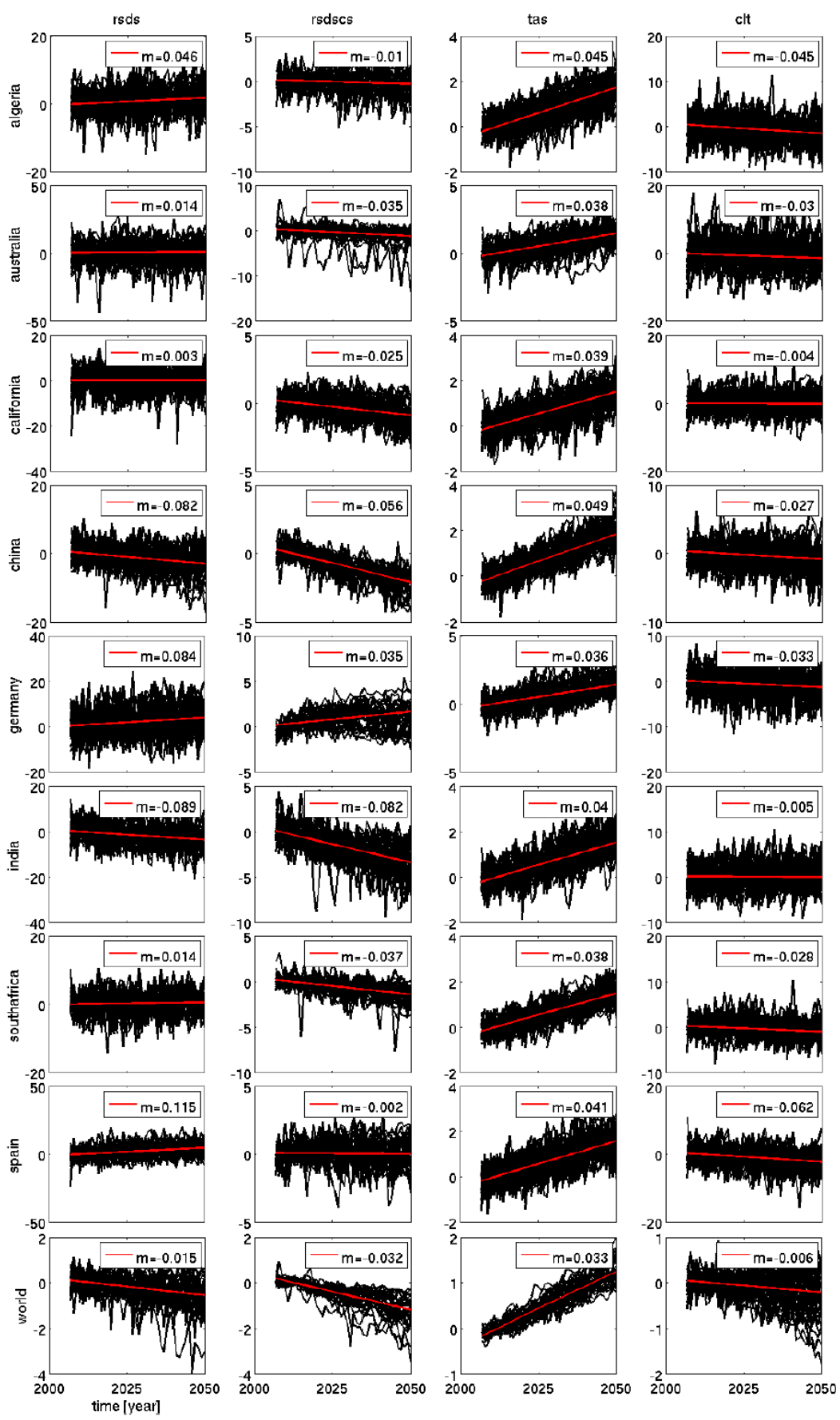

Figure 4: Time series of surface downward solar radiation (rsds) $\left[\mathrm{W} / \mathrm{m}^{2}\right]$, surface downward clear-sky solar radiation ( $\mathrm{rsdscs})\left[\mathrm{W} / \mathrm{m}^{2}\right]$, near surface air temperature (tas) $[\mathrm{K}]$ and total cloud fraction (clt) [\%] for the eight focal regions and the global mean. Shown are deviations from the first decadal mean (2006 to 2015). Each model is represented as a black line, the red lines signify the median of all linear trends applied to the individual model timeseries. Numbers in the panels correspond to slopes of the median trends, units are per year. Note that different panels have different ranges for the y-axis. 

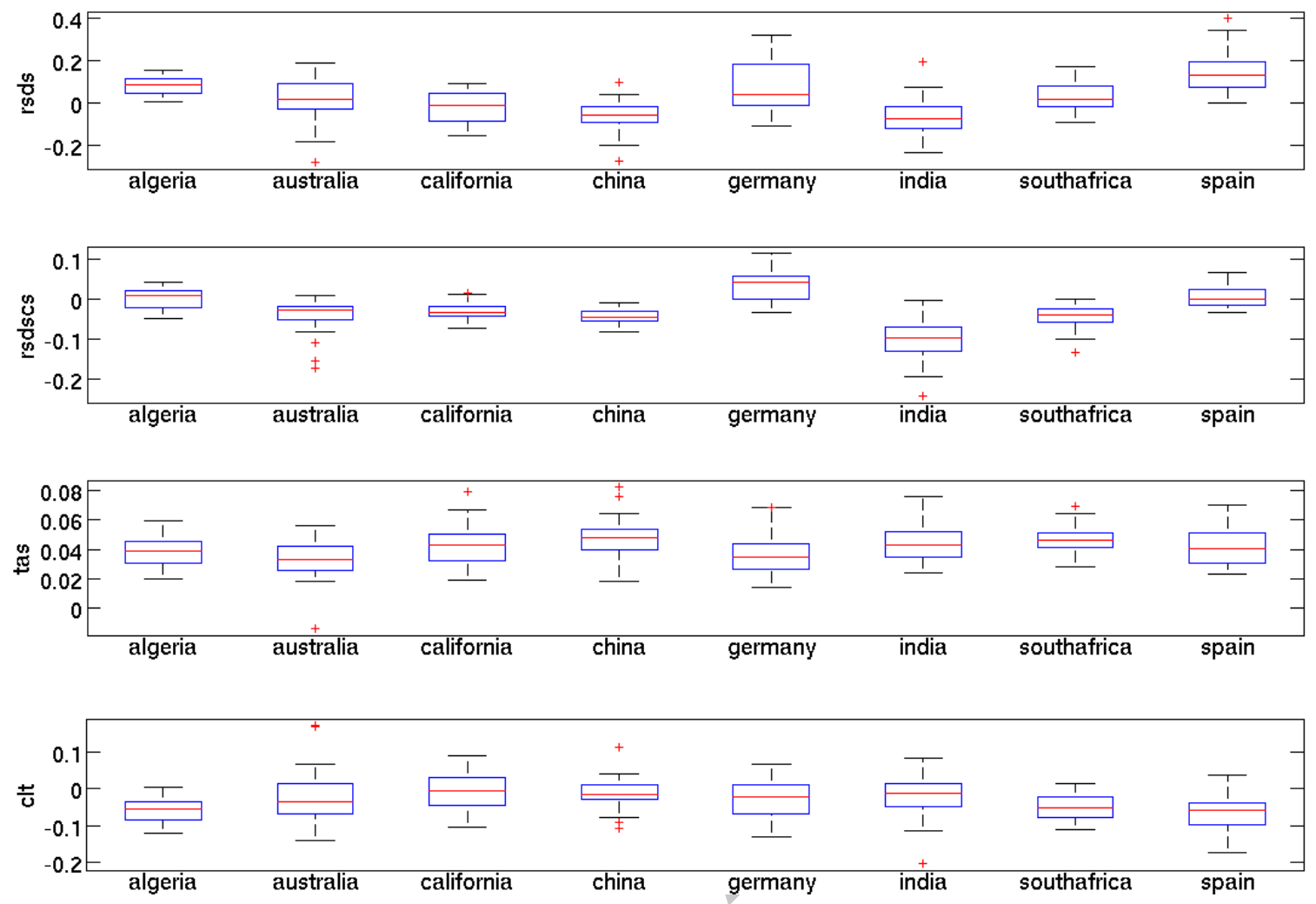

Figure 5: Box plots of the trends of all models between 2006 and 2049 for surface downward solar radiation (rsds) $\left[\mathrm{W} / \mathrm{m}^{2}\right]$, surface downward clear-sky solar radiation (rsdscs) $\left[\mathrm{W} / \mathrm{m}^{2}\right]$, near surface air temperature (tas) $[\mathrm{K}]$ and total cloud fraction (clt) [\%]. Blue lines represent the $25 \%$ and the $75 \%$ quartiles respectively, red lines the medians. Whiskers are presented in black, outliers as red crosses. 


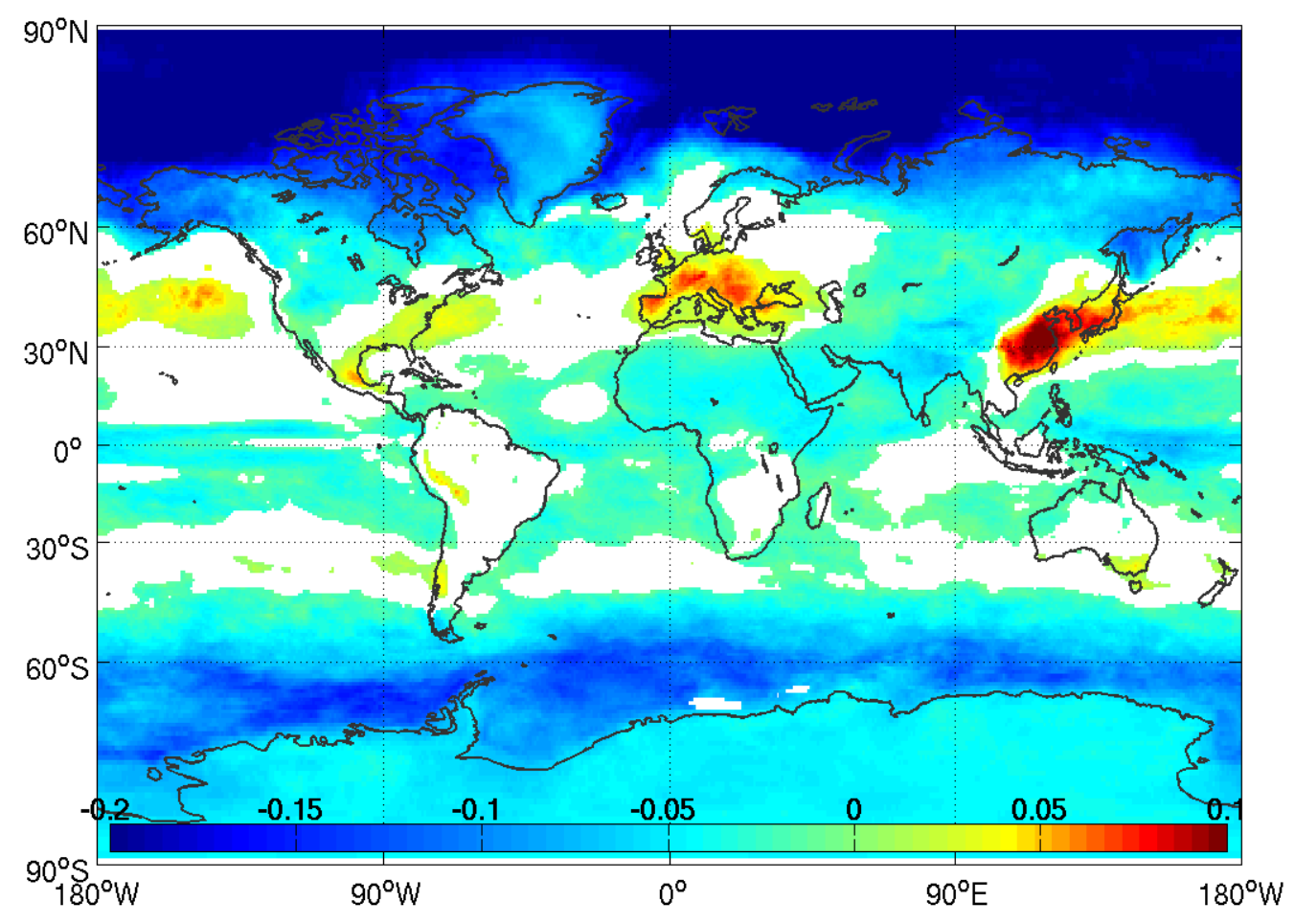

Figure 6: Global distribution of median trends of the fractional change of PV power output between 2006 and 2049. White areas imply non-significant trends, based on a ttest with a significance level of 0.05 . Units are in percent per year. 


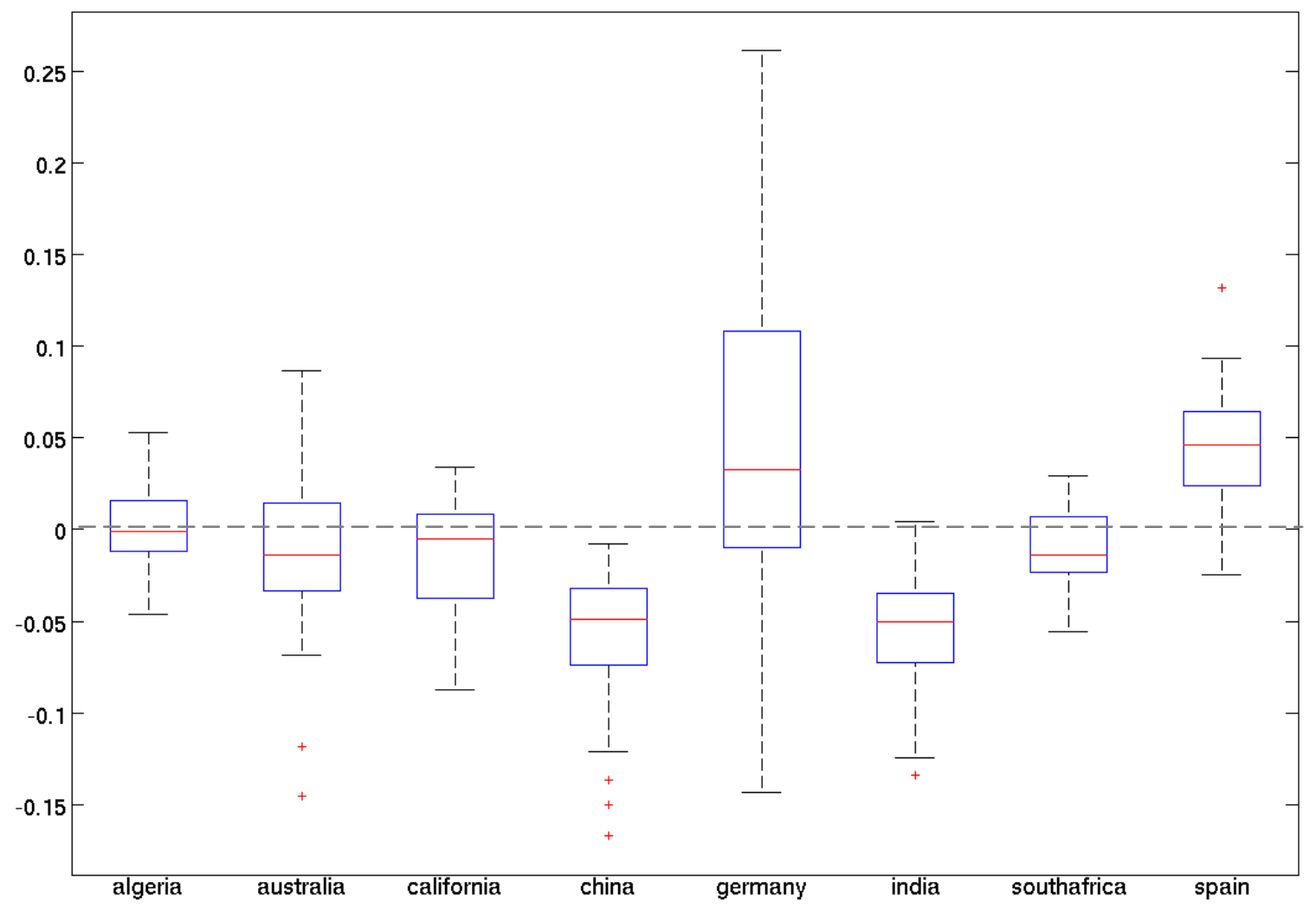

Figure 7: Box plots showing trends of fractional change of PV power output in the focal regions between 2006 and 2049 relative to the first decadal mean (2006 to 2015) based on the 39 models. Units are in \% per year. Blue lines represent the $25 \%$ and the $75 \%$ quartiles respectively, red lines the medians. Whiskers are presented in black, outliers as red crosses. 